\title{
Teaching a Student with Poor Performance in Mathematics to Recall of Multiplication Facts Using Simultaneous Prompting with Systematic Review and Corrective Feedback
}

\author{
Nesrin Sönmez ${ }^{1, *} \&$ Serpil Alptekin ${ }^{2}$ \\ ${ }^{1}$ Special Education, Akdeniz University, Antalya, Turkey \\ ${ }^{2}$ Special Education, 19 Mayıs University, Samsun, Turkey \\ *Correspondence: Special Education, Akdeniz University, Antalya, Dumlupınar Bulvarı, 07058, Campus, Turkey. Tel: \\ 90-242-227-4400/4619. E-mail: ndilersonmez@gmail.com
}

Received: May 15, 2020

doi:10.5430/wje.v10n3p33
Accepted: June 4, 2020 Online Published: June 16, 2020

URL: https://doi.org/10.5430/wje.v10n3p33

\begin{abstract}
In this study, it was aimed to determine the effects of the Simultaneous Prompting (SP) package jointly with the systematic review and corrective feedback in teaching a student with poor performance in mathematics to recall the multiplication facts. One of the single subject designs, the multiple probes design across behaviors (sets) is used in this study. The participant is an 11 years old female student at the 6th grade who has not been diagnosed with any disability but has been getting support because of her poor performance in mathematics than her peers. The dependent variable of this study is the skill of recall multiplication facts with the sets of 3,5 and 8 . The independent variable of the study is the SP package jointly with the systematic review and corrective feedback. Results show that the SP was effective in teaching the student with low mathematical performance to the skill of recall the multiplication facts. The student generalized the learned multiplication facts to another teacher and different setting and maintained her performance on the $15^{\text {th }}$ and $45^{\text {th }}$ days following the systematic reviews. Considering the findings of social validity, it has been determined that the teacher presented positive opinions, as she became happy with that achievement and the method is a way, which can be adopted and implemented by all teachers. These results indicate the acceptability of the SP package and results of the study are highly meaningful. Implications and future research needs are discussed.
\end{abstract}

Keywords: poor performance in math, multiplication facts, simultaneous prompting, systematic review, corrective feedback, drill and practice

\section{Introduction}

Individuals benefit from basic math facts for solving the problems quickly, which they frequently experience in their daily life and need for making calculations. It is based on gaining basic facts sufficiently to do mathematical facts quickly and correctly (Burns, Codding, Boice, and Lukito; 2010; Cates and Ryhmer, 2003; Hudson and Miller, 2006; Shapiro, 2011). Basic facts, which is also a prerequisite for gaining high level mathematical skills in academic life, are the fundamental structures of mathematics and therefore it is aimed by mathematics programs to teach, how to use these skills in an efficient way (Gurganus, 2017; Hasselbring, Goin, and Bransford, 1987; Hinton, Strozier, and Flores, 2014; McCallum and Schmitt, 2011; Mercer and Miller, 1992; Stein, Kinder, Silbert, and Carnine, 2006; Woodward, 2006).

Multiplication, as one of the basic facts, is a strategy used for determining quickly the total of groups, containing more than one equal number of elements (Baykul, 2009; Lampert, 1986; Reys, Lindquist, Lamnbdin, and Smith, 2009). It is necessary to acquire the multiplication related skills in order to do higher level math facts correctly and quickly, such as multiplication without and with carry, fractions, verbal problem solving, calculation with decimal numbers and dividing etc. (Stein et al., 2006; Reys, et al., 2009). In Turkey, it is seen that goals of the multiplication skills are increasingly difficult from the second-grade level to the fourth one in the primary school mathematics program (Ministry of National Education, 2018) and multiplication is taught as a short way of addition. The skill of 
basic multiplication is firstly instructed to students (as the fast and easy way of addition) and then they are memorized the multiplication facts for them to solve multiplication facts at harder levels correctly and fluently (Bender, 2008). Although, it is not right to force students to memorize the multiplication facts, making it easier for them to remember by means of some strategies, is beneficial for them from several respects. Memorization of the multiplication facts and responding it rapidly through this way makes it easier to acquire high level mathematical skills including advance level multiplication, division, solving word problems, fractions and decimal numbers (Bender, 2008; Gagne, 1982; Geary, 2011; Mercer and Miller, 1992; Woodward, 2006).

Acquiring basic mathematical skills is at least as important as acquiring self-care and daily life skills for full participation in daily life (Cawley and Miller, 1989; Erdem, Gürbüz, and Duran, 2011; Hinton et al., 2014; Sayelski and Paulsen, 2010). Therefore, it is significantly important for students with special needs, who have poor mathematical skills to learn basic mathematical skills, like the basic facts. However, students with low mathematics performance have difficulties in gaining basic math skills such as mathematical concepts, number concept, basic facts and digit value, which have a great place in daily life. Difficulties in mathematics are attributed to reasons such as mathematics' hierarchical structure, language problems, poor reading skills, inadequate motor skills, study habits, and ineffective teaching (Gurganus, 2017; Reys et al., 2009; Allsopp, Kyger, and Lovin, 2007). However, no matter how students are ready to learn, if there are no special needs or not, there is no systematic education that includes the elements of effective teaching in well-planned lessons (Alptekin, 2019). Therefore, it is only possible for the students with poor mathematical performance to learn basic mathematical skills, is through systematic instructions, conducted based on the needs of these students (Carnine, 1997; Kame'enui, Carnine, Dixon, Simmons, and Coyne, 2002; Reys et al., 2009; Stein et al., 2006).

Errorless teaching enabling to provide systematic instruction for students contains several strategies. The Simultaneous Prompting (SP) is one of these strategies, and it is a procedure, which minimizes the possibility of students to make an error. The SP is an errorless teaching procedure, which is frequently used, as it does not need establishing any prompt hierarchy, does not need any waiting prerequisite and it is a lean procedure, which is easy to implement (Wolery, Ault and Doyle, 1992). In the SP with proven efficiency in several studies in skills of various developmental fields and disciplines, a controlling prompt is presented immediately after, the target stimulus is presented, and it is expected from the student to perform that skill. It is determined through daily probe sessions done just before teaching sessions, whether the stimulus control is done or not (Gibson and Schuster, 1992; Parrott, Schuster, Collins, and Gassaway, 2000; Sönmez, 2019; Tekin and Kırcaali-İftar, 2001; Wolery et al., 1992).

In the studies researching the effect of the SP in teaching mathematical skills to special needs students with poor mathematical performance, it is observed that the skills of recognizing numbers (Akmanoğlu and Batu, 2004), telling time (Karabulut and Yıkmış, 2010), recognizing numbers and telling time (Birkan, 2005), basic facts (Arı, Deniz, and Düzkantar, 2010; Fickel, Schuster, and Collins, 1998; McCormick, 2014), operations with decimal numbers (Rao and Kane, 2009), recognizing money (Tümeğ and Sazak-Pınar, 2016) identify mathematical symbols (Gürsel, Tekin-İftar and Bozkurt, 2006), solving time problems (Ramirez, Cengher, and Fienup, 2014); Pythagorean Theorem (Creech-Galloway, Collins, Knight, and Bausch, 2013) and determining the number of objects rapidly (Jimenez and Saunders, 2019) are taken into account as the target behaviors which are discrete or chaining. In these studies, it has been determined that, the instructions through the SP is effective in acquiring the selected target behaviors. When the training sessions of the SP is examined in these studies, it is seen that all the implementation steps of the SP process are included. In other words, the processes of giving attention signs by the trainer, presenting the skill direction, giving the controlling prompt and reinforcing the correct responses in the response interval are implemented. In the studies, it is seen that the situations of incorrect responses and no response, was provided feedback in different ways. While the wrong reactions ignored in some studies (Akmanoğlu and Batu, 2004; Tümeğ and Sazak-Pınar, 2016), it is seen that instructive feedback given in other studies (i.e. Birkan, 2005; Gürsel et al., 2006). In our study, the selected target behavior is the skill of recall the multiplication facts and a discrete skill. Recall the multiplication facts have been determined as the target behavior, as it makes it easier to gain the skills for mathematical operations such as multiplication and division of multi-digits with and without carry.

Two studies have been found in the literature related with teaching multiplication through the SP, where one of the studies was on students with mild cognitive impairment and one on the typically developing students. Rao and Mallow (2009) implemented the SP procedure in order to bring in two students with cognitive impairment the skill to recall 30 multiplication facts between $0-12$ correctly. 30 multiplication facts containing multiplication facts of the aimed numbers between $0-12$ were written on $3^{\prime \prime} \times 5^{\prime \prime}$ flash cards. 5 cards were presented through the SP in each instructional session. The next set was instructed when a student has completed the multiplication facts in the set provided consecutively at least in two sessions at $100 \%$ accuracy. After each session, daily probe sessions including 
asking 30 multiplication facts, were arranged with the subjects. One of the subjects has gained the whole skill during the daily probe session in the $18^{\text {th }}$ day while the other in the $24^{\text {th }}$ day.

Drevon and Reynolds (2018) compared the effectiveness and efficiency of the Response Repetition (RR) which is an error-correction procedure and the SP for acquisition and maintenance the multiplication facts in their study conducted on 3 students at the $3^{\text {rd }}$ grade with typical developmental characteristics. In the study, 24 multiplication facts with the numbers between 0-12 were written on $3^{\prime \prime}$ x 5 " flash cards. In each instructional session, the set made up of 8 multiplication facts were presented in turns of 4 with the RR and 4 with the SP. In instructional trials of the $R R$, the multiplication fact on the flash card was shown to the subjects and the answer was asked and if they answered incorrectly, an example was set for the correct answer and it was requested from the subject to repeat the operation and the result for the $5^{\text {th }}$ and the last time. In the instructional trials conducted through the SP, the multiplication facts and its result on the flash card were read and then the target stimulus were presented by the researcher. Wrong answers were ignored and no feedback was provided. During daily probe sessions, the 8 presented facts were asked. At the end of the instructions, performance of students increased in both, while the RR ensured both subjects to do all multiplication facts correctly. However, the SP was found more efficient with regards to number of errors and the time for achieving the criteria.

In order to improve efficiency of students in mathematics, it is important to bring in the ability of fast, effortless and correct recall, which is necessary in mathematics for solving problems and facts (McVancel, Missall and Bruhn, 2018). It is only possible by efficiently planning systematic review-based repetition drill and practice to ensure acquiring recall requiring target skills such as multiplication table and making it easier for students to keep what they learn in their minds (Alptekin, 2019; Carnine, 1997; Kame'enui et al., 2002). Carnine, Dixon and Kame'enui (1994) defined four principles for efficient review: The first of them is that the systematic review are sufficient in number enough for the students to present their skill without any hesitation; the second one is distributing over time, the third one is must be cumulative and the fourth and last one is that practices are varied enough to illustrate applying information on various situations. And in this study, the drill and practice ensuring the students to systematic review what they have learned were done for teaching the multiplication facts by distributing over time through several cumulative repetitions jointly with the SP. By this way, it is considered the problem of unable to achieve the criteria of the study of Drevon and Reynolds (2018) can be resolved by adding several cumulative repetitions distributed over time in the SP instructional package. In addition to this, apart from two previous studies, an error correction has been done in this study by providing corrective feedback while implementing the SP.

It is expected that this study will provide contribution in the literature as there are a few numbers of studies where the $\mathrm{SP}$ is used for teaching the multiplication facts. In addition, it is considered that it is an original study with regards to including the drill and practices which provide systematic review of skills learned among the studies conducted with individuals with special needs. Therefore, the purpose of this study is to determine the effectiveness of SP instructional package jointly with the systematic review and corrective feedback in teaching a student with poor performance in mathematics to recall the multiplication facts. This study addressed the following research questions: (1) Is SP instructional package effective in teaching a student with poor performance in mathematics to recall the multiplication facts? (2) Will the student be able to maintain the performance, she has achieved, over time? (3) Will the student be able to generalize the recall multiplication facts she has learned across other setting and persons? (4) What are teacher's opinions about the social importance of the study?

\section{Method}

\subsection{Participant}

The student (Ayşe, not her real name) who participated this study is an 11 years' old female student at the 6th grade who has not been diagnosed with any disability but who is getting support because of her poor performance in mathematics than her peers. Her intelligence score has been determined as 70, as a result of a WISC-R test, which was applied in the Psychiatry Clinic of the Medicine Faculty of a state university. Ayşe has been provided 3 hours weekly individual special education service for 20 months, as of the starting date of the study, in a research center of the same university, which provides education services for children with developmental delay. In this center, firstly the teacher and then the parent meetings were held by second author and in accordance with the opinions of the teacher and the parents, it was determined that Ayşe was showing significant deficiency in mathematical skills compared to her peers. Then, the "Mathematic Checklist", developed by the researchers of this study, which is directly based on observation, was applied on her. While developing the checklist, it was decided first what information to gather. It is aimed to collect information in counting, basic facts, digit value and verbal problem 
solving which are the basic math skills. After the area to gather information was determined, the sub-skills of the related skills were examined by investigating the mathematics curriculum, mathematics textbooks and auxiliary books. Later, these skills were lined up from easy to difficult, and statements of the checklist were created. This checklist was made up of 40 statements, serving to assess basic mathematical skills. In addition, the questions that serve to measure each statement were prepared and the criteria were determined. The implementer (i.e. second author) organized the test atmosphere and sat face to face with the student. Then, the she asked the questions in statements in the order by means of materials and papers, which she previously prepared. As, the checklist was ordered from easy to hard, the test was ended in the first statement, which the student could not solve. Under the light of the information obtained by applying the checklist, it was determined that Ayşe was capable of addition of multiple digit numbers with and without carry, subtraction of multi digit numbers by differentiating and not differentiating decimals, skip counting, basic multiplication (as a shortcut to addition) and replacement of numbers in multiplication. It is possible to study recall the multiplication facts with students who have the skills of skip counting and basic multiplication (Hudson and Miller, 2016; Reys et al., 2009; Stein et al., 2006). As a result of the observations, it was determined that Ayşe had the skills of skip counting and basic multiplication (as a shortcut to addition) as pre-requisites for recall the multiplication facts.

\subsection{Trainer}

All sessions of the study have been conducted by a teacher working as a class teacher of students with intellectual disability in the research center where the study is conducted. She is a graduate of special education department. She had 8 years of experience and she has been working at the center where the research has been carried out for the last two years. She is also the participant's teacher and has been working with the student for two years. The teacher training (TT) has been provided her by the researcher (i.e., second author). The TT included a 60 minutes oral presentation on collecting data and how to conduct the training through the SP. The contents of the TT on collecting data were made up of the topics of preparing setting, describing rules to the student, presenting directions, observing the reactions of the student and recording. The contents of the training through the SP were made up of preparing materials, preparing setting, introduction to the study, indicating an attention sign, implementing the SP package, assessing and recording the progresses of student and ending the instruction. The written text related with how to conduct the procedure after completing the training, was submitted to the teacher. Then, it was requested from her to carry out a pre-training with another student and it was recorded on video. Then, the records were watched together with the researcher and feedbacks were provided. Furthermore, the same records were watched by both researchers and a reliability assessment was conducted separately for collecting data and the training. The teacher showed $99 \%$ reliability rate in collecting data and $98 \%$ in the training.

\subsection{Setting}

In the research, all data collection and teaching sessions were held in an approximately 8 square meter classroom located in the center. All items, objects and toys that will attract the student's attention have been removed from the setting. Instruction was in a 1:1 arrangement. In the setting, there is a table and two chairs where the teacher and the student will sit side by side. The student and the teacher sat face to face at a table suitable for the student's height. There are the record sheet and a pencil in front of the teacher in data collection sessions. There are a worksheet and a pencil in front of the student. In the teaching sessions held with SP, the worksheet and pencil are in front of the student and the progress chart in front of the teacher.

\subsection{Materials}

Table 1. Multiplication Facts Sets

\begin{tabular}{lll}
\hline Set 1 & Set 2 & Set 3 \\
\hline $3 \times 4$ & $5 \times 4$ & $8 \times 4$ \\
$3 \times 6$ & $5 \times 6$ & $8 \times 6$ \\
$3 \times 8$ & $5 \times 8$ & $8 \times 8$ \\
$3 \times 2$ & $5 \times 2$ & $8 \times 2$ \\
$3 \times 5$ & $5 \times 5$ & $8 \times 5$ \\
$3 \times 1$ & $5 \times 1$ & $8 \times 1$ \\
$3 \times 9$ & $5 \times 9$ & $8 \times 9$ \\
$3 \times 7$ & $5 \times 7$ & $8 \times 7$ \\
$3 \times 3$ & $5 \times 3$ & $8 \times 3$ \\
\hline
\end{tabular}


In the study, 3 teaching sets, included multiplication facts by 3, 5 and 8 were established. Each of these sets was made up of 9 multiplication facts from $\mathrm{x} 1$ to $\mathrm{x} 9$ (see Table 1). In order to eliminate the possibility of correct answers by the subject through skip counting, the multiplications in these sets were presented to her in a composite order.

\subsection{Research Design}

One of the single subject research designs, the multiple probe design across behaviors (sets) was used in this study. The multiple probe design across behaviors is a design, where efficiency of an independent variable on three different behaviors is examined (Alberto and Troutman, 2009; Tekin-İftar, 2012). This design was used in the study in order to determine the effects of the SP on teaching recall multiplication facts across three different training sets to a participant. The dependent variable of the study was recall the multiplication facts of $3 \mathrm{~s}, 5 \mathrm{~s}$ and $8 \mathrm{~s}$, which were selected as the target behavior. Multiplication facts with 3 different numbers which were not multitudes of each other was determined in order to prevent influence learning of one on learning of others. The independent variable of the study was the training through the SP package jointly with the systematic review and corrective feedback. In order to see the effect of the independent variable on the dependent variable, three sets made up of multiplications with $3 \mathrm{~s}, 5 \mathrm{~s}$ and $8 \mathrm{~s}$ were presented in order, when $100 \%$ success was achieved in the first set, other set was begun to be taught and a different multiplication set was presented in each and every time. In addition, while the training was continuing in a set, the probe data was collected for the other sets. Experimental control was established by presenting the independent variable in each training set in a specific order (Kırcaali-İftar and Tekin, 1997; Tawney and Gast, 1984; Tekin-İftar, 2012).

\subsection{Measures}

In the study, the baseline, probe, training, review, generalization and maintenance data were collected for each set in order to determine the effects of the SP package on acquisition, generalization and maintenance levels in the target skills. In addition to these, the reliability data was collected by conducting reliability assessments of the dependent and the independent variables and the social validity data was collected for determining the importance of results with social regards.

"The Data Record Form" was developed in order to collect the baseline, probe, training, review, generalization and maintenance data. This form was made up of the columns where the name and surname of the student, the date, the baseline, the multiplication facts in related set and the student's answers were recorded. While collecting data, the multiplication facts in related set were asked to the student one by one and the responses of her were recorded in the Data Record Form. For example: if, the student responded correctly when, it was asked to the student, "what is 3 times 4", (+) mark was input in the form and then passed to the question of next fact. If, the student responded wrong, a (-) mark was input in the form and then passed to the question of next fact. If, the student did not respond at all or responded hesitantly (such as, answering right at first and then wrong or vice versa), that question was asked again and if the responses continued in the same way, a (-) mark was input in the form. When, all facts were completed, the test was ended. The training data were collected through "the Progress Chart". The name and surname of the student, duration of training, date and skill steps were included in the chart and the assessment and training sessions columns were included in the skill steps column.

Furthermore, the reliability data was also collected in the study by conducting reliability assessments of the dependent and the independent variables. The interobserver reliability data has been collected in order to test the reliability of the dependent variable, while the procedural reliability data has been collected in order to test the reliability of the independent variable. The interobserver reliability and the procedural reliability data collection forms were developed for reliability assessments. During collecting study data and the training, the behaviors of the trainer and the participant were recorded on video and $30 \%$ of these video recordings were assessed by the researchers, independent from each other.

In order to collect social validity data of the study, the social validity form for the teacher which was developed by the researchers was used. The social validity form for the teacher served for determining the strengths and weaknesses of the training through the SP package, the kind of changes the target skills would cause on the student and whether they would be useful for her to learn following skills and take advantage in her daily life based on the opinions of the teacher. There were 11 questions in total in the form as 8 of them were close-ended and 3 of them were open-ended. After, the training sessions was completed, the teacher was submitted this form and asked to respond these questions.

\subsection{Analysis of Data}

The efficiency, generalization and maintenance data of the study was indicated graphically and analyzed visually. 
The horizontal axis of the graphic indicates the number of sessions while the vertical axis indicates the number of multiplication facts answered correctly by the student. In the study, the social validity data was analyzed by means of descriptive analysis techniques. In the study, the agreement / agreement + disagreement x 100 formulation (Erbaş, 2012; Miles and Huberman, 1994; Tawney and Gast, 1984) has been used for analyzing the interobserver reliability data. The interobserver reliability data related with the reliability of the data collected in each phase of the study is presented in the Table 2 .

Table 2. Interobserver Reliability Data

\begin{tabular}{lllllll}
\hline & Baseline & Probe & Training & Review & Maintenance & Generalization \\
\hline Set 1 & $\% 100$ & $\% 100$ & $\% 100$ & $\% 100$ & $\% 100$ & $\% 100$ \\
Set 2 & $\% 100$ & $\% 100$ & $\% 100$ & $\% 100$ & $\% 100$ & $\% 100$ \\
Set 3 & $\% 100$ & $\% 100$ & $\% 100$ & $\% 100$ & $\% 100$ & $\% 100$ \\
\hline
\end{tabular}

As it can be seen from Table 2, the reliability value related with the independent variable was found $100 \%$ reliable in all sessions.

In the study, the analysis of the procedural reliability has been calculated by dividing the observed behaviors of the teacher to the planned behaviors of the teacher and multiplying it with 100 (Billingsley, White and Munson, 1980). Both researchers watched the $30 \%$ of the randomly selected records of the training. The data related with the training sessions, where procedural reliability data was collected, is presented in Table 3.

Table 3. Procedural Reliability Data

\begin{tabular}{llll}
\hline Training Steps & Set 1 & Set 2 & Set 3 \\
\hline Material Preparation & $\% 100$ & $\% 100$ & $\% 100$ \\
Setting Preparation & $\% 100$ & $\% 100$ & $\% 100$ \\
Introduction to the Training & $\% 100$ & $\% 100$ & $\% 100$ \\
Giving an Attention Signal & $\% 100$ & $\% 100$ & $\% 100$ \\
Implementing the SP & $\% 100$ & $\% 100$ & $\% 100$ \\
Assessing and Recording the Progresses of the Student & $\% 100$ & $\% 100$ & $\% 100$ \\
Completing the Training & $\% 100$ & $\% 100$ & $\% 100$ \\
\hline
\end{tabular}

As it is seen from Table 3, the teacher was found 100\% reliable in implementing all phases of the training sessions in all sets.

\section{Procedure}

The training took 22 working days excluding the maintenance sessions and the review sessions which were conducted for the final set. For each set, the baseline, training, review, generalization and maintenance sessions were conducted.

\subsection{Baseline Sessions}

Baseline data was calculated 3 consecutive times before starting the training.

\subsection{Probe Sessions}

While, the baseline and training sessions were continuing at a set in order to determine the effect of the SP in acquiring a target behavior, the probe data was collected for once in the second set while twice in the third set.

\subsection{Training Sessions}

Duration of the training sessions conducted through SP was 15 minutes. The training sessions of the study were conducted as six sessions in the first set and five sessions in the second and the third sets. Two trials were conducted in each session. The duration between these trials was determined as 5 seconds. The rules of training were explained to the student in the beginning of each session, the award was shown, the record chart was introduced, and the training was initiated by giving the attention signal. Then, the target stimulus was presented by the teacher to the student ("3 times 2 equals 6"). Immediately after, the skill directive was presented to the student ("now, your turn, 
what is 3 times $2 ")$. If, the student responded correctly within 5 seconds, it was determined as a progress for the student and the related column of the record chart, was input a (+) mark. If, the student did not respond within 5 seconds or responded wrong, the correct answer was provided through a corrective feedback and the related column of the record chart was input a (-) mark and the target stimulus for the following multiplication fact was presented. Also, an assessment was conducted in the beginning of each training session and data was collected during the training. The multiplication facts of the set were asked one by one in the beginning of training of each set and the responses of the student were marked on the Progress Record Chart. The training sessions were continued until the student correctly answered all multiplication facts of the training set in three consecutive assessments. When, the training of a new set was started, the review sessions were held for the previously learned set. Trainings were carried out in the similar manner for each set.

\subsection{Systematic Review Sessions}

Three systematic review sessions were held for each set. The data related with review sessions was collected for 3 times in cumulative way by distributed over time in a way where the previous set was repeated when the training of a new set was started while continuing training other sets. The teacher asked the multiplication facts in related set in order to the student during these review sessions and if, the student responded wrong, she immediately provided feedback by giving the correct answer. For example, if, the student did not respond the question of what is 5 times 5 , correct or if she did not respond at all, the correct result of the multiplication as "5 times 5 equals 25 " was provided. The wrong reactions were marked on the Data Record Form as (-).

\subsection{Generalization Sessions}

The generalization data was collected immediately after the review sessions by a different teacher who was in another class.

\subsection{Maintenance Sessions}

The maintenance data was collected in the $15^{\text {th }}$ and $45^{\text {th }}$ days after completing the training and review sessions of each set.

\section{Results}

Within the scope of the study, results obtained on the efficiency, generalization, maintenance and social validity were represented.

\subsection{Efficiency}

The efficiency findings of the participant are the following findings for set 1.

As it is shown in Figure 1, Ayşe responded 4, 5 and 4 correct answers in the baseline assessments conducted in 3 consecutive sessions for multiplications of 3 . After, the baseline phase, 6 training sessions were conducted with Ayşe. Considering the Figure 1, Ayșe achieved the criterion by correctly responding all multiplications of 3 beginning from the $4^{\text {th }}$ session of the training phase and she showed a consistent performance for three consecutive sessions. Considering the probe data of the second and third sets collected during the same process, it was observed that she answered 4 multiplications of 5 and 8, correctly. It was observed that the performance shown by Ayşe in the first probe session of the second set (while, collecting the baseline data of the first set was being collected), was maintained during the baseline phase (while, the training sessions conducted through the SP package were continued for the first set). Likewise, it was observed that the performance shown by her during the first probe session of the third set (while, collecting the baseline data of the first set was being collected), was maintained during the following probe session (while, the baseline session data was collected for the second set).

The findings of the participant are the following findings for set 2 .

According to Figure 1, Ayşe answered 4 of the multiplication facts asked to her in each session during the baseline assessments collected in 3 consecutive sessions of the multiplication facts with 5. The training sessions with Ayşe for multiplication facts with 5 continued 5 sessions in total. Ayşe responded all multiplication facts correctly beginning from the third training session and showed a consistent performance for three consecutive training sessions. It was seen by examining the probe data of the third training session collected during the same process that she responded three of multiplication facts with 8. In the probe sessions during the third set, it was observed that Ayşe maintained her performance she showed during the first probe session (while, the baseline data was collected during the first set and the probe data was collected during the second set) also for the second probe session (while, the review sessions were conducted during the first set and the baseline data was collected during the second set). 
The findings of the participant are the following findings for set 3 .

As it is seen from Figure 1, Ayşe gave respectively 4, 3 and 4 correct answers for baseline assessments of the multiplication facts in the third set, where multiplications with 8 were included. The training sessions with Ayşe for multiplication facts with 8 continued 5 training sessions in total. Ayşe responded all multiplication facts correctly beginning from the third training session and showed a consistent performance for three consecutive training sessions.

As it is shown in Figure 1, the curves obtained from the data from all sets became distant from the curves of the baseline level. In addition to this, as the curves of probes in other sets were at the same level, while training sessions were continuing during another set; it was considered that the change observed on the student was related with the SP package. As a result, the trainings conducted through the SP were found efficient and effective for acquiring in the student the multiplication facts with 3,5 and 8 for all three sets.

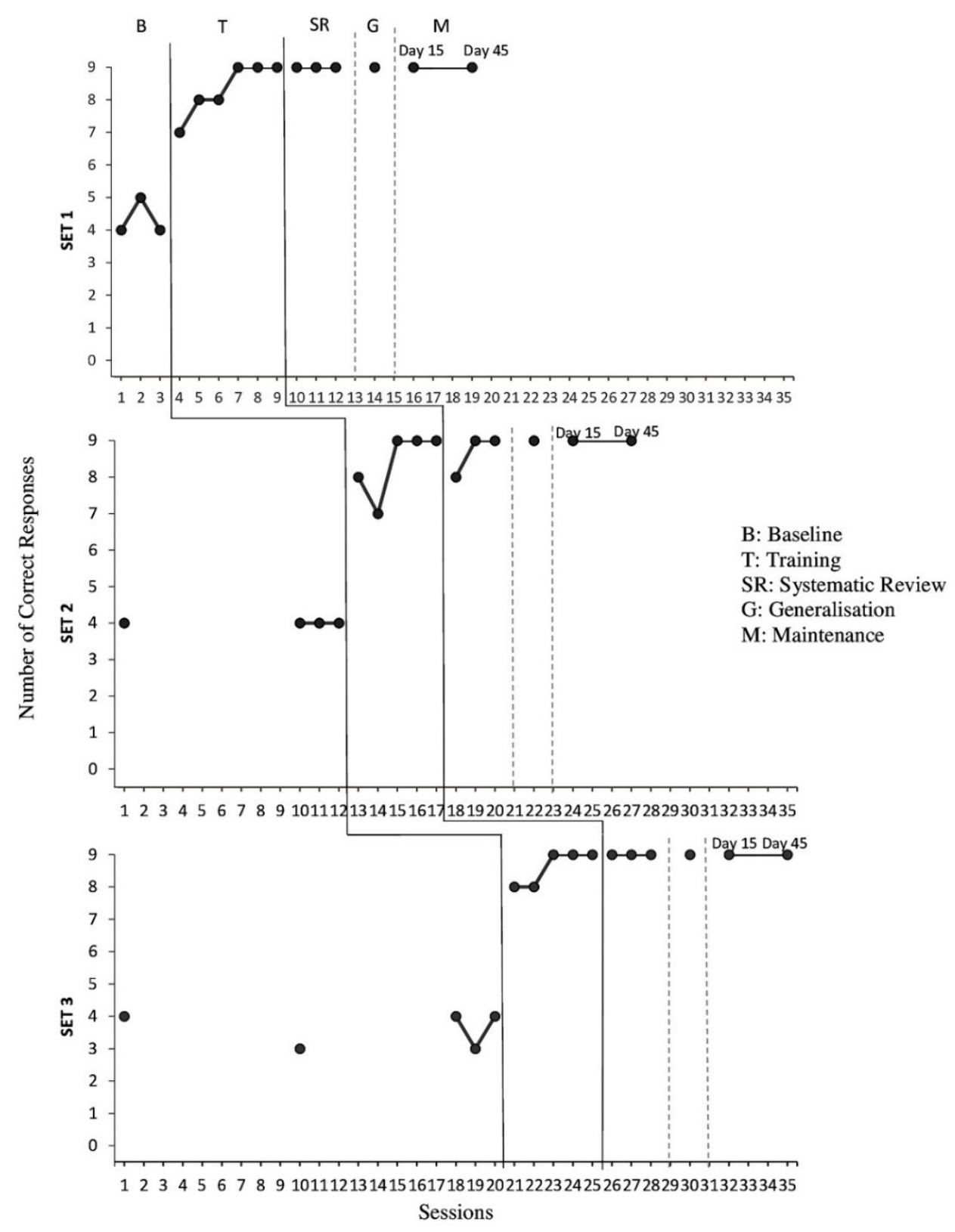

Figure 1. Number of Correct Response during Baseline, Training, Systematic Review, Generalization and Maintenance Sessions for Ayse 
After, the training sessions, the dependent variable of the study, in other words, the review data for consecutive 3 training sessions following training of each set for determining her level of performance in multiplications of 3 , 5 and 8 was collected. The student responded all multiplication facts with 3 in three consecutive sessions during the review assessments conducted after the training. In the first session of the review session conducted after training of multiplications with 5, she responded 8 questions correctly, then all of them in two other consecutive sessions. During three sessions of the review conducted after training multiplications with 8 , she responded all multiplication facts correctly in all these three sessions.

\subsection{Generalization}

The generalization level data collected in the session following the end of the review sessions of the set taught is given in Figure 1. In the generalization session conducted in another class with another teacher Ayşe exhibited the performance observed in the review sessions by responding all multiplications with 3, 5 and 8 . It was observed that Ayşe generalized her skill to recall multiplication facts, which she acquired, to every set, other class and teacher.

\subsection{Maintenance}

In order to determine whether Ayşe maintained her acquisition level in multiplication facts with 3, 5 and 8 from a while after the training sessions of the SP package, the maintenance data was collected in the $15^{\text {th }}$ and $45^{\text {th }}$ days after the end of the training. As it is seen from Figure 1, Ayşe responded all multiplication facts of all three sets with 3, 5 and 8 correctly in the $15^{\text {th }}$ and $45^{\text {th }}$ days after the training. Therefore, it was considered that the SP package was effective for her to maintain her performance obtained in all three sets.

\subsection{Social Validity}

Considering the social validity findings, 6 closed-ended and 2 open-ended questions were asked to the teacher (i.e. trainer) just after the training phase of the study was completed. These questions included the strengths and weaknesses of the SP package, what kind of changes the target behaviors would create in the student and whether they would be useful for learning future skills and her daily life. The teacher's answers were gathered under three themes. These themes are (1) impact on subsequent learning, (2) effectiveness, and (3) practice in different conditions. Regarding the effect on subsequent learning, the teacher stated that the student who gained basic multiplication in this way could learn more difficult multiplication and division facts more easily. In relation to effectiveness, she stated that she had previously done non-systematic repetitions and gave homework, but in this way, she could not gain the student the skill. She also stated that teaching with SP gives the student the opportunity to conduct many systematic teaching trials and that regular repetitions contribute to this. She stated that the SP was useful, that she would prefer to use it in other students and in the teaching of different skills, and that she would recommend it to other teacher friends to use. In addition, the student was followed by the researcher (i.e. second author) and it was observed that the student gained more difficult multiplication and division facts after training.

\section{Discussion}

In the study, the SP instructional package provided to a student with poor mathematical performance, jointly with systematic review that distributed over time and conducted through several cumulative repetitions, and jointly with corrective feedback, was found effective in gaining the skill of recall the multiplication facts (multiplications with 3 , 5 and 8). This finding fits the findings of Rao and Mallow (2009), the only study conducted with individuals in special needs on teaching recall the multiplication facts. In addition to this, this finding is parallel to the findings of the studies, which indicate that, the SP is effective in teaching different mathematical skills (Akmanoğlu and Batu, 2004; Arı et al., 2010; Fickel et al., 1998; Karabulut and Y1kmış, 2010). Consequently, as there are a limited number of studies in teaching recall the multiplication facts, it can be said that the SP is an effective procedure for teaching mathematical skills to students with poor mathematical performance.

In this study, corrective feedback was provided to wrong responses of the student during training sessions through the SP package. In the only previous study on the subject conducted with students with special needs, it was seen that the wrong responses were ignored while teaching the multiplication facts through the SP (Rao and Mallow, 2009). On the other hand, in the study where the effects of Response Repetition (RR) and the SP were compared (Drevon and Reynolds, 2018), wrong responses were ignored in the training sessions conducted through the SP procedure. In the study of Drevon and Reynolds (2018), corrective feedbacks were provided to the student during training sessions conducted through RR and it was also ensured that the student responded the correct answer for 5 times. In the training sessions where the SP was implemented, like the study of Rao and Mallow (2009), wrong responses were ignored, and no response repetition was done. At the end of the study, it was concluded that the RR was more 
effective for two students and had a similar effect for one student. Although, their study was conducted with typically developing students, this result might be based on not providing any corrective feedback during training sessions through the SP. From this perspective, it can be recommended for instructors to apply corrective feedback, while teaching through the SP. However, it is not sufficient to indicate that, only based on the result of this study. Several studies are needed for determining the effects of the corrective feedback in trainings through the SP.

The generalization related findings of the study show that a student with poor mathematical performance generalizes her performance that she acquired conducted the training session, to a different setting and other teacher. In the study of Rao and Mallow (2009), it was concluded that two students with mild cognitive impairment could generalize the multiplication facts they learned to another environment, to other persons and other materials. The generalization findings, which were obtained in other studies where various target skills are brought in through the SP, show similarity (Akmanoğlu and Batu, 2004; Birkan, 2005; Gürsel et al., 2006; Rao and Kane, 2009). Consequently, it can be said that the SP procedure is effective in causing generalization for teaching mathematical skills. Considering that improving academic success of students is an important variable for increasing their social acceptance (Lewis and Doorlag, 1999; Maag and Webber, 1995; Mastropieri and Scruggs, 2004; Salend, 2001), the importance of showing mathematical skills in different environments in the presence of different people, becomes apparent.

In the study, it is concluded that training package through the SP is effective in maintaining the learned multiplication facts. This result coincides with the results of the previous study (Rao and Mallow, 2009), where a student with mild cognitive impairment was taught the multiplication facts. In both studies, the skill of recall the multiplication facts is a single-step discrete skill. Likewise, in the literature studies where the effects of discrete skills (Akmanoğlu and Batu, 2004; Birkan, 2005; Gürsel et al., 2006; Karabulut and Yıkmış, 2010; Tümeğ and Sazak-Pınar, 2016), as well as the chained skills (Ar1 et al., 2010; Creech-Galloway et al., 2013; Rao and Kane, 2009), in teaching mathematic through the SP on various dependent variables, it was observed that the participants maintained the target skill they gained through that training procedure. It is suggested that cumulative drills by distributing over time as one of the principles of efficient review for implementing permanent learning in teaching mathematical skills is necessary (Hudson and Miller, 2006; Stein et al., 2006). The purpose of systematic review sessions is to provide correction, when the student makes a mistake and improve maintenance of the skills which she has learned. It is only possible by efficiently planning systematic review-based drill and practices to ensure gaining recollection requiring target skills such as multiplication table and making it easier for students to keep what they learn in their minds (Alptekin, 2019; Carnine, 1997; Kame'enui et al., 2002). In this study, the number of drill and practices distributing over time and cumulative, three of four principles defined by Carnine et al., (1994) for efficient review and repetition exercises, are included. However, in order to provide experimental control, the principle of providing diversity enough to illustrate the application of information to different situations could not be included in the drill and practices. In this study, apart from previous studies, when, teaching of a set was started by completing teaching another set, review sessions were conducted by cumulatively repeating the previously learned sets. From this point of view, the importance of cumulative, distributed over time for maintaining recall the multiplication facts can be emphasized. However, it is not accurate to come to a certain judgment from the data obtained in this study. McVansel et al., (2018) indicates that there are a fewer number of studies analyzing the effects of cumulative drill and practices in mathematics compared to other disciplines. In accordance with this, planning studies, where the trainings with and without systematic review sessions, might be a suggestion for future studies.

In the social validity findings of the study, the teacher (i.e. trainer) presented positive opinions as the SP is a useful, feasible and recommendable procedure. In addition to this, she indicated that she could not make the student recall the multiplication facts even after implementing several teaching methods; it made her happy to succeed when she conducted this instructional package, education through the SP provided opportunity to the student for making several trials and regular repetitions provided great contribution to that. These positive opinions of the teacher on the SP procedure show that, this is a procedure, which can be adopted and used by other teachers and the social validity of the study results, are also high for the teacher. In two previous studies on teaching the multiplication facts through the SP, no social validity finding was collected. However, it is observed that social validity data was collected in relatively a fewer number of studies, where the effects of teaching through the SP for teaching different target skills were studied. The data of these studies coincide with the data obtained in this study (Akmanoğlu and Batu, 2004; Ar1 et al., 2010; Tümeğ and Sazak-Pınar, 2016). In other studies, data of social validity was collected by discussing the issue with teachers or parents, while no social data of validity was collected by discussing it with students. In this study, the social validity data was collected only by discussing the issue with the teacher and no issue related social validity data of parents and/or the student was collected. Consequently, the social validity findings of the study are limited with the teacher's opinions. 
It is considered that this study will be a guide for the experts, researchers and teachers working in the discipline of this study for bringing in students the skill of recall the multiplication facts by means of the SP. However, it should be noted that the results obtained from this study are limited with the student participated in it and the multiplications of 3, 5 and 8, taught to that student. In this direction, several studies can be replicated by conducting with several subjects. In addition to this, new studies can be designed on whether it is possible or not to obtain similar results from students with prerequisite skills, who have autism, intellectual or learning disabilities. The effects of this study, which was conducted through one-to-one teacher-student interaction, can be examined by conducting a similar study on a group. The effects of instructional packages, where corrective feedback is included and not, can be examined for the trainings conducted through the SP procedure. Furthermore, efficiency studies, which will reveal the effects of cumulative distributed over time on recall multiplication facts more than this study, can be planned. Studies, where efficiency and effectiveness of various prompting systems in recall the multiplication facts from memory, can also be conducted.

\section{Acknowledgements}

This article was presented as an oral presentation at the "27 $7^{\text {th }}$ International Conference on Educational Sciences (ICES/UEBK-2018)" on 18-22 April 2018 in Antalya.

Conflicts of Interest: The authors declare no conflict of interest.

\section{References}

Akmanoğlu, N., \& Batu, S. (2004). Teaching pointing to numerals to individuals with autism using simultaneous prompting. Education and Training in Developmental Disabilities, 39(4), 326-336.

Alberto, P. A., \& Troutman, A. C. (2009). Applied behavior analysis for teachers (9th ed.). Colombus: OH: PrenticeHall.

Alptekin, S. (2019). Planning mathematics for effective teaching. In S. Alptekin (Ed.), in Mathematics in special education: Teaching basic math skills to students with low mathematics performance (pp. 1-19). Ankara, Turkey: Eğiten Kitap.

Allsopp, D. H., Kyger, M. M., \& Lovin, L. H. (2007). Teaching mathematics meaningfully solutions for reaching struggling learners. New Jersey: Paul H. Brookes Publishing.

Arı, A., Deniz, L., \& Düzkantar (Uysal), A. (2010). The effectiveness of simultaneous prompting procedure on teaching addition and subtraction operations to a mentally handicapped child. Abant İzet Baysal University Journal of Faculty of Education, 10(1), 49-68.

Baykul, Y. (2009). Teaching mathematics in primary education: 1-5 for grades (10th ed.). Ankara, Turkey: Pegem Akademi.

Bender, W. N. (2010). Learning disabilities: Characteristics, identification, and teaching strategies (6th ed.). Boston: Pearson/Allyn and Bacon.

Billingsley, F. F., White, O. R., \& Munson, R. (1980). Procedural reliability: A rationale and an example. Behavioral Assessment, 2, 229-241.

Birkan, B. (2005). Using simultaneous prompting for teaching various discrete tasks to students with mental retardation. Education and Training in Developmental Disabilities, 40(1), 68-79.

Burns, M. K., Codding, R. S., Boice, C. H., \& Lukito, G. (2010). Meta-analysis of acquisition and fluency math interventions with instructional and frustration level skills: Evidence for a skill by treatment interaction. School Psychology Review, 39(1), 69-83.

Carnine, D. (1997). Instructional design in mathematics for students with learning disabilities. Journal of Learning Disabilities, 30(2), 130-141. https://doi.org/10.1177/002221949703000201

Carnine, D. W., Dixon, R. C., \& Kame'enui, E. J. (1994). Math curriculum guidelines for diverse learners. Curriculum/Technology Qarterly, 3(3), 1-3.

Cates, G. L., \& Rhymer, K. N. (2003). Examining the relationship between mathematics anxiety and mathematics performance: An instructional hierarchy perspective. Journal of Behavioral Education, 12(1), 23-34. https://doi.org/10.1023/A:1022318321416 
Cawley, J. F., \& Miller, J. H. (1989). Cross-Sectional comparisons of the mathematical performance of children with learning disabilities are we on the right track toward comprehensive programming? Journal of Learning Disabilities, 22(4), 250-254. https://doi.org/10.1177/002221948902200409

Creech-Galloway, C., Collins, B. C., Knight, V., \& Bausch, M. (2013). Using a simultaneous prompting procedure with an iPad to teach the Pythagorean Theorem to adolescents with moderate intellectual disability. Research \& Practice for Persons with Severe Disabilities, 38(4), 222-232. https://doi.org/10.1177/154079691303800402

Drevon, D. D., \& Reynolds, J. L. (2018). Comparing the effectiveness and efficiency of response repetition to simultaneous prompting on acquisition and maintenance of multiplication facts. Journal of Behavioral Education, 27, 358-374. https://doi.org/10.1007/s10864-018-9298-7

Erbaş, D. (2012). Reliability. In E. Tekin-İftar (Ed.), Single-subject research in education and behavioral sciences (pp. 109-128). Ankara, Turkey: Turkish Psychological Association Publications.

Erdem, E., Gürbüz, R., \& Duran, H. (2011). An investigation of mathematics used in daily life from past to present: Theory out practice in. Turkish Journal of Computer and Mathematics Education (TURCOMAT), 2(3), $232-246$.

Fickel, K. M., Schuster, J. W., \& Collins, B. C. (1998). Teaching different tasks using different stimuli in a heterogeneous small group. Journal of Behavioral Education, 8, 219-244. https://doi.org/10.1023/A:1022887624824

Gagne, R. M. (1982). Some issues in psychology of mathematics instruction. Journal of Research in Mathematics Education, 14(1), 7-18. https://doi.org/10.2307/748793

Geary, D. C. (2011). Cognitive predictors of achievement growth in mathematics: A 5-year longitudinal study. Developmental Psychology, 47(6), 1539-1552. https://doi.org/10.1037/a0025510

Gibson, A. N., \& Schuster, J. W. (1992). The use of simultaneous prompting for teaching expressive word recognition to preschool children. Topics in Early Childhood Special Education, 12(2), 247-267. https://doi.org/10.1177/027112149201200208

Gurganus, S. P. (2017). Math instruction for learning problems (2th ed.). New York: Routledge. https://doi.org/10.4324/9781315684499

Gürsel, O., Tekin-Iftar, E., \& Bozkurt, F. (2006). Effectiveness of simultaneous prompting in small groups: The opportunity of acquiring non-target skills through instructive feedback and observational learning. Education and Training in Developmental Disabilities, 41(3), 225-243.

Hasselbring, T. S., Goin, L. I., \& Bradsford, J. D. (1987). Effective math instruction: Developing automaticity. Teaching Exceptional Children, 19(3), 30-33. https://doi.org/10.1177/004005998701900309

Hinton, V., Strozier, S. D., \& Flores, M. M. (2014). Building mathematical fluency for students with disabilities or students at-risk for mathematics failure. International Journal of Education in Mathematics, Science and Technology, 2(4), 257-265. https://doi.org/10.18404/ijemst.69677

Hudson, P., \& Miller, S. (2006). Designing and implementing mathematics instruction for students with diverse learning needs. Boston: Pearson Education, Inc.

Jimenez, B., \& Saunders, A. (2019). Increasing efficiency in mathematics: Teaching subitizing to students with moderate intellectual disability. Journal of Developmental and Physical Disabilities, 31, 23-37. https://doi.org/10.1007/s10882-018-9624-y

Kame'enui, E. J., Carnine, D. W., Dixon, R. C., Simmons, D. C., \& Coyne, M. D. (2002). Effective teaching strategies that accommodate diverse learners (2nd ed.). New Jersey: Merrill Prentice Hall.

Karabulut, A., \& Y1kmış, A. (2010). The effectiveness of simultaneous prompting on teaching the skill of telling the time to individuals with mental retardation. Abant Izzet Baysal University Journal of Faculty of Education, 10(2), 103-113.

Kurcaali-İftar, G., \& Tekin, E. (1997). Single-subject research methods. Ankara, Turkey: Turkish Psychological Association Publications.

Lampert, M. (1986). Knowing, doing, and teaching multiplication. Cognition and Instruction, 3(4), $305-342$. https://doi.org/10.1207/s1532690xci0304 1

Lewis, R. B., \& Doorlag, H. D. (1999). Teaching special students in general education classrooms. New Jersey, Prentice Hall. 
Maag, J. W., \& Webber, J. (1995). Promoting children's social development in general education classrooms. Preventing School Failure, 39(3), 13-19. https://doi.org/10.1080/1045988X.1995.9944629

Mastropieri, M. A., \& Scruggs, T. E. (2004). The inclusive classroom: Strategies for effective instruction (2nd ed.). Columbus, OH: Prentice Hall/Merrill.

McCallum, E., \& Schmitt, A. J. (2011). The taped problems intervention: Increasing the math fact fluency of a student with an intellectual disability. International Journal of Special Education, 26(3), 276-284.

McCormick, A. E. (2014). The effects of a simultaneous prompting procedure to teach math skills during play time to young children with developmental disabilities. Theses and Dissertations-Early Childhood, Special Education, and Rehabilitation Counseling, 6. Retrieved from https://uknowledge.uky.edu/edsrc_etds/6

McVancel, S. M., Missall, K. N., \& Bruhn, A. L. (2018). Examining incremental rehearsal: Multiplication fluency with fifth-grade students with math IEP goals. Contemporary School Psychology, 22, 220-232. https://doi.org/10.1007/s40688-018-0178-x

Mercer, C. D., \& Miller, S. P. (1992). Teaching students with learning problems in math to acquire, understand, and apply basic math facts. Remedial and Special Education, 13(3), 19-35. https://doi.org/10.1177/074193259201300303

Miles, M, B., \& Huberman, A. M. (1994). Qualitative data analysis: An expanded sourcebook (2nd ed.). Thousand Oaks, CA: Sage.

Ministry of National Education. (2018). Mathematics curriculum. Retrieved from http://mufredat.meb.gov.tr/Programlar.aspx

Parrott, K. A., Schuster, J. W., Collins, B. C., \& Gassaway, L. J. (2000). Simultaneous prompting an instructive feedback when teaching chained tasks. Journal of Behavioral Education, 10, 3-19. https://oi.org/10.1023/A:1016639721684

Ramirez, H., Cengher, M., \& Fienup, D. M. (2014). The effects of simultaneous prompting on the acquisition of calculating elapsed time. Children with Autism Journal of Developmental and Physical Disabilities, 26, 763-774. https://doi.org/10.1007/s10882-014-9394-0

Rao, S., \& Kane, M., T. (2009). Teaching students with cognitive impairment chained mathematical task of decimal subtraction using simultaneous prompting. Educationand Training in Developmental Disabilities, 44(2), 244-256

Rao, S., \& Mallow, L. (2009). Using simultaneous prompting procedure to promote recall of multiplication facts by middle school students with cognitive impairment. Education and Training in Developmental Disabilities, 44(1), 80-90.

Reys, R., Lindquist, M. M., Lamnbdin D. V., \& Smith, N. L. (2009). Helping children learn mathematics (9th ed.). USA: John Wiley \& Sons, Inc.

Salend, S. J. (2001). Creating inclusive classrooms: Effective and reflective practices (4th ed.). Columbus, OH: Merrill/Prentice Hall.

Sayelski, K. L., \& Paulsen, K. J. (2010). Mathematics reform curricula special education: Identifying intersections and implications for practice. Intervention in School and Clinic, 46(1), 13-21. https://doi.org/10.1177/1053451210369515

Shapiro, E. S. (2011). Academic skills problems, direct assessment and intervention (4th ed.). New York: Guilford Press.

Sönmez, N. (2019). Teaching math skills by errorless teaching practices. In S. Alptekin (Ed.), in Mathematics in special education: Teaching basic math skills to students with low mathematics performance (pp. 421-456). Ankara, Turkey: Eğiten Kitap.

Stein, M., Kinder, D., Silbert, J., \& Carnine, D. (2006). Designing effective mathematics instruction: A direct instruction approach (3rd ed.). New Jersey: Pearson Prentice Hall.

Tawney, J. W., \& Gast, D. L. (1984). Single subject research design in special education. Columbus, OH: Merrill.

Tekin-İftar, E. (2012). Models of multiple probe. In E. Tekin-İftar (Ed.), in Single-subject research in education and behavioral sciences (pp. 217-243). Ankara, Turkey: Turkish Psychological Association Publications. 
Tekin, E., \& Kircaali-Iftar, G. (2001). Errorless learning procedures in special education. Ankara, Turkey: Nobel Yayınevi.

Tümeğ, S., \& Sazak Pınar, E. (2016). The effectiveness of simultaneous prompting teaching procedure on teaching coins to students with intellectual disabilities by a peer with intellectual disabilities. Ankara University Faculty of Educational Sciences Journal of Special Education, 17(3), 269-297. https://doi.org/10.21565/ozelegitimdergisi.267317

Wolery, M., Ault, M. J., \& Doyle, P. M. (1992). Teaching students with moderate to severe disabilities. New York: Longman Publishing Group.

Woodward, J. (2006). Developing automaticity in multiplication facts: Integrating strategy instruction with timed practice drills. Learning Disability Quarterly, 29(4), 269-289. https://doi.org/10.2307/30035554 